\title{
NOTA
}

\section{CORRELAÇÃO ENTRE LEITURAS DE CLOROFILA E NÍVEIS DE NITROGÊNIO APLICADOS EM FEIJOEIRO $\left({ }^{1}\right)$}

\author{
ENES FURLANI JUNIOR $\left({ }^{2}\right)$, JULIO NAKAGAWA $\left({ }^{3}\right)$, LUCIANO JOSÉ BULHÕES $\left({ }^{3}\right)$, \\ JOSÉ ALUISIO ALVES MOREIRA $\left({ }^{4}\right)$ e HÉLIO GRASSI FILHO $\left({ }^{3}\right)$
}

\begin{abstract}
RESUMO
Foram realizados dois ensaios, sendo um em solução nutritiva e outro em solo, utilizando seis níveis de nitrogênio $(28,56,84,112,140$ e $168 \mathrm{mg} / \mathrm{L}$ de $\mathrm{N})$ a fim de ajustar as leituras diretas, feitas nas folhas de feijoeiro, com um clorofilômetro (Minolta SPAD-501), aos níveis crescentes de nitrogênio e ao seu teor nas folhas. Avaliaram-se os parâmetros: área foliar; massas dos materiais verde e seco; teor de clorofila; produção de grãos e teores de $\mathrm{N}, \mathrm{Ca}, \mathrm{Mg}$ e $\mathrm{S}$. Todos esses dados, mais as leituras do aparelho, foram correlacionados entre si e com os níveis de $\mathrm{N}$ aplicados. As correlações positivas entre as leituras e os níveis de $\mathrm{N}$ fornecidos $(\mathrm{R}=0,86)$ e entre as leituras e os teores de $\mathrm{N}$ nas folhas $(\mathrm{R}=0,75)$ indicam que há perspectivas favoráveis quanto ao uso desse equipamento para detectar deficiências de nitrogênio em feijoeiro.
\end{abstract}

Termos de indexação: clorofila, nitrogênio, feijão, clorofilômetro.

\section{ABSTRACT \\ CORRELATION BETWEEN CHLOROPHYLL CONTENT AND NITROGEN LEVELS APPLIED ON BEAN LEAVES}

Two experiments were carried out at greenhouse conditions in nutrient solution and soil, using six nitrogen levels $(28,56,84,112,140$ and $168 \mathrm{mg} / \mathrm{L}$ of $\mathrm{N}$ ) to adjust the chlorophyll meter readings (Minolta SPAD-501) to the nitrogen levels in the bean leaves. Chlorophyll content, leaf area, fresh and dry matter of leaves, N, $\mathrm{Ca}, \mathrm{Mg}$ and $\mathrm{S}$ leaf concentration, and grain yield were evaluated. Good correlations were obtained between chlorophyll meter readings and nitrogen application rates

( $\left.{ }^{1}\right)$ Recebido para publicação em 11 de outubro de 1994 e aceito em 23 de outubro de 1995.

(2) Seção de Algodão, Instituto Agronômico (IAC), Caixa Postal 28, 13001-970 Campinas (SP).

(3) FCA/UNESP, Caixa Postal 237, 18603-970 Botucatu (SP).

(4) EMBRAPA, CNPAF - Goiânia (GO). 
$(R=0.86)$ and leaf nitrogen concentration $(R=0.75)$. These results indicate that the chlorophyll meter is a useful device to detect nitrogen deficiency in bean plants.

Index terms: chlorophyll, nitrogen, beans, chlorophyll meter.

É do conhecimento da literatura e da prática, a importância do nitrogênio na produtividade da cultura do feijoeiro. A avaliação prática é a observação de uma clorose generalizada das folhas, iniciando-se pelas folhas mais velhas, sempre que ocorre a sua deficiência no solo. Caballero et al. (1985) relatam que o acúmulo de matéria seca do feijoeiro é diretamente proporcional ao suprimento adequado de nitrogênio para a planta. Tal fato está relacionado à função estrutural do nitrogênio na molécula de clorofila. Dessa forma, na falta do nitrogênio fornecido via solo, a planta degrada a molécula de clorofila, retranslocando o $\mathrm{N}$ para regiões de crescimento ativo. O nitrogênio é um dos elementos essenciais que não possuem um método eficaz para avaliar a sua carência no solo. As recomendações para adubação nitrogenada baseiam-se em curvas de absorção do nutriente e acúmulo de matéria seca pela planta (Cobra Neto et al., 1971). Além desse fato, ocorrem perdas do nutriente no solo devido, principalmente, ao excesso de água, com conseqüente lixiviação do nitrogênio. Dessa forma, recomenda-se adubação em cobertura, no período de máximo crescimento da planta (Meirelles et al., 1980), para a obtenção de melhores níveis produtivos.

Em vista, principalmente, das possíveis perdas de nitrogênio ocorridas durante a adubação de cobertura e do máximo acúmulo de matéria seca pela planta, faz-se necessária a determinação da época mais adequada para a adubação nitrogenada em cobertura. Recentemente, colocou-se, no mercado, o aparelho Minolta SPAD-501, de leitura indireta de clorofila e utilizável no campo.

Há uma equação que fornece a quantidade de clorofila estabelecida para algumas culturas, tais como o trigo-sarraceno, a batatinha e o arroz, mas não para o feijoeiro. Considerando esses dois aspectos, realizaram-se dois ensaios objetivando ajustar as leituras diretas, feitas no aparelho, com teor de nitrogênio e verificar se a equação estabelecida para outras culturas poderá ser aplicada ao feijoeiro, em termos de teor de clorofila.

\section{Material e Métodos}

Inicialmente, montou-se em casa de vegetação, no Departamento de Solos da FCA/UNESP, Câmpus de Botucatu, um ensaio em solução nutritiva, obedecendo ao esquema criado por Hoagland \& Arnon (1950), utilizando-se os seguintes níveis de nitrogênio em solução nutritiva: $28,56,84,112,140$ e $168 \mathrm{mg} / \mathrm{L}$ de $N$. Esta solução foi preparada e mantida em estoque, sempre repondo aos recipientes, quando o nível diminuía, de acordo com o tratamento. Foram utilizadas sementes do cultivar de feijão Carioca, que foi germinado em areia e transplantado para o recipiente com solução nutritiva em torno de 8 dias após a emergência. Aos 30 dias do transplantio, efetuou-se uma leitura do teor de clorofila, com o clorofilometro, na segunda folha verdadeira do feijoeiro. Esse experimento foi interrompido aos 40 dias do transplantio, sendo os dados de leitura de clorofila e teor de clorofila (estimado pela equação $y=0,0996 \times-0,152)$ submetidos a uma análise de regressão, correlacionados aos níveis crescentes de nitrogênio. O delineamento experimental foi o inteiramente casualizado, com seis tratamentos e quatro repetições.

Posteriormente, montou-se outro ensaio, também em casa de vegetação, porém com plantas envasadas. Cada vaso continha três litros de solo, tendo sido efetuada a análise de solo com a posterior correção de fósforo e potásssio com a aplicação de $3,664 \mathrm{~g}$ de superfosfato triplo e $0,0313 \mathrm{~g}$ de $\mathrm{KCl}$ por vaso, para a correção de deficiência de $\mathrm{P}$ e $\mathrm{K}$, além da calagem, sendo a aplicação de nitrogênio efetuada nos seguintes níveis: $168 ; 140$; $112 ; 84 ; 56$ e $28 \mathrm{mg} / \mathrm{L}$ de nitrogênio por vaso, aplicando-se metade da dose na semeadura, metade em cobertura, na forma de sulfato de amônio. A semeadura foi efetuada em 27/4/90, colocando-se cinco sementes por vaso e, posteriormente, o desbaste, 
deixando-se duas plantas por vaso. Quando as plantas atingiram duas folhas verdadeiras (34 dias após a semeadura), efetuou-se a aplicação do sulfato de amônio em cobertura nas doses citadas. O delineamento experimental utilizado foi o inteiramente casualizado, com seis tratamentos e quatro repetições. Passados 42 dias da semeadura, efetuou-se a leitura de clorofila, na segunda folha verdadeira do feijoeiro, média de 15 leituras por folíolo, coletando-se as mesmas folhas, para a obtenção da área foliar, massa dos materiais verdes e secos e teores de $\mathrm{N}, \mathrm{Ca}, \mathrm{Mg}$ e S. Efetuou-se, ainda, a colheita de grãos de cada vaso, 90 dias após a semeadura. Tais dados foram submetidos à análise da variância convencional, com médias comparadas pelo teste de Tukey a $5 \%$ de probabilidade, e verificados os níveis de correlação $(R)$ entre as variáveis, através da análise de regressão (obtenção de equações de regressão).

\section{Resultados e Discussão}

A área foliar, a matéria verde e seca e os teores de $\mathrm{Ca}, \mathrm{Mg}$ e $\mathrm{S}$ não foram influenciados pelos níveis de $\mathrm{N}$, mas os teores de clorofila e nitrogênio e a produção de grãos foram afetados praticamente na razão direta dos níveis de nitrogênio adicionados (Quadro 1). O quadro 2, contendo os coeficientes de correlações obtidos, entre vários pares, confirma os resultados da análise da variância do quadro 1 . Efetivamente, as doses de $\mathrm{N}$ correlacionaram-se significativamente com as leituras do aparelho (clorofilômetro). Outras correlações significativas encontradas foram entre os seguintes pares: leitura de clorofila $\mathrm{x}$ teor de $\mathrm{N}$ nas folhas; teor de $\mathrm{N}$ nas folhas com teor de clorofila (estimado pela equação $y=0,0996 \times-0,152)$.

Estabelecendo-se as equações de regressão, para as correlações significativas, supramencionadas, sugere-se que, nos próximos ensaios, sejam utilizados intervalos entre níveis menores nas doses iniciais e maiores nas finais, aumentando a probabilidade de melhores curvas. As curvas mais significativas encontram-se no quadro 2, correlacionando leituras do aparelho com doses de $\mathrm{N}$ aplicadas e teores de $\mathrm{N}$ nas folhas, respectivamente, mostrando a sensibilidade do aparelho às quantidades de $\mathrm{N}$ no solo e suas conseqüências nas plantas. Tais correlações fornecem ainda a perspectiva de calibrar a leitura do aparelho a doses a serem aplicadas para uma produtividade ótima, conforme se pode verificar pela correlação entre $\mathrm{N}$ aplicado e massa de grãos,

Quadro 1. Valores médios de área foliar, matéria verde e seca das folhas, teor de clorofila, massa de grãos, teores de $\mathrm{N}, \mathrm{Ca}, \mathrm{Mg}$ e $\mathrm{S}$, em feijoeiro (ensaio em vaso)( ${ }^{\mathrm{l}}$ )

\begin{tabular}{lccccccc}
\hline \multirow{2}{*}{ Valores médios } & \multicolumn{7}{c}{$\mathrm{N} / \mathrm{kg}$ de solo $(\mathrm{mg})$} \\
\cline { 2 - 7 } & $\mathrm{CV}(\%)$ & 28 & 56 & 84 & 112 & 140 & 168 \\
\hline Área foliar $\left(\mathrm{cm}^{2}\right)$ & 14,20 & 212 & 262 & 249 & 310 & 295 & 277 \\
Matéria verde $(\mathrm{g})$ & 14,58 & 4,67 & 5,94 & 5,43 & 6,08 & 6,21 & 6,26 \\
Matéria seca $(\mathrm{g})$ & 23,78 & 0,64 & 0,85 & 0,74 & 0,69 & 0,82 & 0,83 \\
Clorofila $\left(\mathrm{mg} / 100 \mathrm{~cm}^{2}\right)$ & 4,48 & $2,93 \mathrm{c}$ & $3,15 \mathrm{bc}$ & $3,16 \mathrm{bc}$ & $3,37 \mathrm{ab}$ & $3,43 \mathrm{ab}$ & $3,62 \mathrm{a}$ \\
Massa de grãos $(\mathrm{g})$ & 21,60 & $15,09 \mathrm{~b}$ & $20,02 \mathrm{ab}$ & $27,75 \mathrm{ab}$ & $20,78 \mathrm{ab}$ & $32,70 \mathrm{a}$ & $30,25 \mathrm{a}$ \\
$\mathrm{N}(\mathrm{g} / \mathrm{kg})$ & 7,69 & $60,8 \mathrm{~b}$ & $68,5 \mathrm{ab}$ & $70,0 \mathrm{ab}$ & $77,1 \mathrm{a}$ & $74,2 \mathrm{a}$ & $79,4 \mathrm{a}$ \\
Ca $(\mathrm{g} / \mathrm{kg})$ & 22,3 & 163 & 133 & 181 & 166 & 164 & 170 \\
$\mathrm{Mg}(\mathrm{g} / \mathrm{kg})$ & 14,1 & 67 & 59 & 88 & 74 & 76 & 79 \\
$\mathrm{~S}(\mathrm{~g} / \mathrm{kg})$ & 27,4 & 45 & 47 & 61 & 75 & 82 & 88 \\
\hline
\end{tabular}

( ) Os contrastes significativos estão assinalados com letras diferentes e o DMS foi feito pelo teste de Tukey a $5 \%$ de probabilidade. 
Quadro 2. Equações e coeficientes de correlação obtidos mediante análise de regressão linear entre os parâmetros avaliados aos níveis de $1 \%(* *)$ e $5 \%$ (*)

Variável independente $x$

$\mathrm{N}$ nas folhas $(\mathrm{g} / \mathrm{kg})$

$N$ nas folhas $(\mathrm{g} / \mathrm{kg})$

Níveis de $\mathrm{N}$ em solução nutritiva

Níveis de $\mathrm{N}$ apl. solo

Níveis de $\mathrm{N}$ apl. solo

Níveis de $\mathrm{N}$ apl. solo
Variável dependente $\mathrm{y}$

Leitura

Matéria seca

Leitura

Leitura

Matéria seca

Área foliar $\left(\mathrm{cm}^{2}\right)$
Equação

Correlação (R) que apresentou um valor de $\mathrm{R}=0,68$, o qual não foi apresentado nos quadros constantes deste trabalho devido à não-significância estatística a $5 \mathrm{e}$ $1 \%$ de probabilidade. No entanto, através da calibração das doses, como citado anteriormente, são boas as possibilidades de utilização do aparelho na indicação da deficiência de $\mathrm{N}$ em feijoeiro.

As respostas obtidas, no presente trabalho, quanto à aplicação de nitrogênio e sua implicação no desenvolvimento do feijoeiro, estão de acordo com os resultados obtidos por Ben et al. (1977), Cunha et al. (1980), Almeida et al. (1982) e Caballero et al. (1985), os quais verificaram um aumento de produtividade, mediante aplicação de níveis crescentes de nitrogênio em feijoeiro.

Embora a fixação simbiótica de nitrogênio seja responsável por cerca de $68 \%$ do nitrogênio total na planta (Ruschel \& Ruschel, 1982), o período de máxima fixação para o cultivar Carioca situa-se entre 60 e 70 dias (Ruschel et al., 1975). Dessa forma, segundo Rosolem (1987), a absorção ocorrerá numa fase posterior àquela em que a planta tem a sua exigência máxima do nutriente, podendo explicar assim alguns trabalhos com resposta à adubação nitrogenada.

Dessa forma, a detcrminação do momento ideal de adubação nitrogenada é de suma importância, para um bom desenvolvimento e produtividade do feijoeiro.

As equações do quadro 2 evidenciam que os níveis de nitrogênio aplicados em solução nutritiva e em vaso têm uma resposta linear, para a leitura de clorofila, matéria seca e área foliar. Tal fato também pode ser observado entre teores de nitrogênio encontrados nas folhas e leitura de clorofila e teores de $\mathrm{N}$ e matéria seca. Deve-se ressaltar a similaridade das equações, que correlacionam os níveis de $\mathrm{N}$ e as leituras de clorofila, em solução nutritiva e em vaso.

Tal fato evidencia a precisão do aparelho, abrindo, assim, a possibilidade de sua utilização, como instrumento para avaliação da carência do nutriente na planta e a necessidade da adubação de cobertura.

\section{Conclusões}

1. Tanto no ensaio em solução nutritiva como no de vaso utilizando solo, as leituras feitas nas folhas em função de níveis de $\mathrm{N}$ proporcionaram valores de $\underline{a}$ e $\underline{b}$ bem próximos para a função y $=a+b x$, refletindo bem os níveis de nitrogênio fornecidos ao feijoeiro.

2. Ocorreram excelentes correlações entre a leitura e os níveis fornecidos e a leitura e os teores de $\mathrm{N}$ nas folhas.

3. Há boas perspectivas em poder detectar deficiência de $\mathrm{N}$ apenas com a leitura direta, sem calcular o teor de clorofila, bem como a viabilidade de corrigir adequadamente a carência de nitrogênio em função dessas leituras e, como vantagem adicional, essa técnica pode fornecer a informação de forma não destrutiva, rápida e eficaz. 


\section{REFERÊNCIAS BIBLIOGRÁFICAS}

ALMEIDA, L.D'A. de; BULISANI, E.A.; GALLO, P.B. \& SABINO, J.C. Resposta de três cultivares de feijoeiro à adubação nitrogenada. In: REUNIÃO NACIONAL DE PESQUISA DE FEIJÃO, 1., Goiânia, 1982. Anais. Goiânia, EMBRAPA-CNPAF, 1982. p.184-187.

BEN, J.R.; HARTZ, H. \& SCHERER, E. Resposta da cultura do feijoeiro (Phaseolus vulgaris L.) ̀̀ adubação nitrogenada em um latossolo roxo distrófico. In: REUNIÃO ANUAL DO FEIJÃO, Porto Alegre, 1977. Anais. Porto Alegre, IPA, 1977. 14 p.

CABALLERO, S.U.; LIBARDI, P.L.; REICHARDT, K.; MATSUI, E. \& VITÓRIA, R.L. Utilização do fertilizante nitrogenado aplicado a uma cultura de feijão. Pesquisa Agropecuária Brasileira, Brasília, 20(9):1031-1040, 1985.

COBRA NETO, A.; ACCORSI, W.R. \& MALAVOLTA, E. Estudos sobre a nutrição mineral do feijoeiro (Phaseolus vulgaris L. var. Roxinho). Anais da Escola Superior de Agricultura 'Luiz de Queiroz', Piracicaba, 28:257-274, 1971.

CUNHA, J.M. da; GUAZZELLI, R.J.; DALLACQUA, F.M. \& FERNANDES, D.C. Níveis de nitrogênio na cultura do feijão. Pesquisa Agropecuária Brasileira, Brasília, 15(1):47-53, 1980.

HOAGLAND, D.R. \& ARNON, D.I. The water culture method for growth plants without soil. Bekerley, University of California, 1950. (Circular 347)

MEIRELLES, N.M.F.; LIBARDI, P.L. \& REICHARDT, K. Absorção e lixiviação de nitrogênio em cultura de feijão (Phaseolus vulgaris L.). Revista Brasileira de Ciência do Solo, Campinas, 4(2):83-88, 1980.

ROSOlEM, C.A. Nutrição e adubação do feijoeiro. Piracicaba, Associação Brasileira para Pesquisa da Potassa e do Fosfato, 1987. 93 p. (Boletim técnico, 8)

RUSCHEL, A.P. \& RUSCHEL, R. Avaliação da fixação simbiótica de nitrogênio em feijão. Pesquisa Agropecuária Brasileira, Rio de Janeiro, 10(11):1117, 1975.

RUSCHEL, A.P.; VOSE, P.B.; MATSUI, E.; VITORIA, R.L. \& SAITO, S.M.T. Field evaluation of $\mathrm{N}_{2}$ fixation and nitrogen utilization by Phaseolus bean varieties determined by $15 \mathrm{~N}$ isotope dilution. In: REUNIĀO NACIONAL DE PESQUISA DE FEIJÃO, 1., Goiânia, 1982. Anais. Goiânia, EMBRAPACNPAF, 1982. $316 \mathrm{p}$. 